\title{
Transmission X-Ray microscopy of the galvanostatic growth of lead sulfate on lead: Impact of lignonsulfonate
}

\author{
K. W. Knehr ${ }^{\mathrm{a}, 1}$, Christopher Eng ${ }^{\mathrm{b}}$, Jun Wang ${ }^{\mathrm{b}}$, and Alan C. West ${ }^{\mathrm{a}}$ \\ ${ }^{a}$ Department of Chemical Engineering, Columbia University, New York, NY 10027, USA \\ ${ }^{\mathrm{b}}$ Photon Sciences Directorate, Brookhaven National Laboratory, Upton, NY 11973, USA
}

To be submitted as a Technical Paper to

Electrochimica Acta, 2015

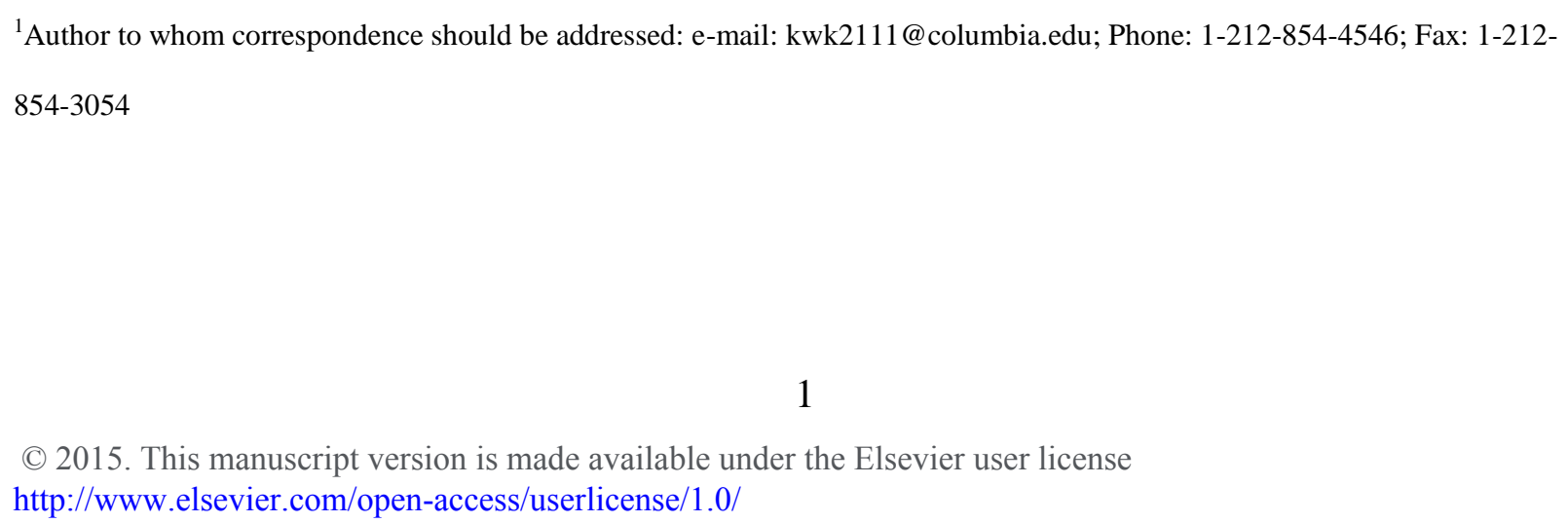




\begin{abstract}
The galvanostatic growth of $\mathrm{PbSO}_{4}$ on $\mathrm{Pb}$ in $\mathrm{H}_{2} \mathrm{SO}_{4}$ was studied using scanning electron microscopy and in situ transmission x-ray microscopy (TXM). Images from the TXM are used to investigate the effects of sodium lignosulfonate on the $\mathrm{PbSO}_{4}$ formation and the initial growth of the $\mathrm{PbSO}_{4}$ crystals. Sodium lignosulfonate is shown to retard, on average, the growth of the $\mathrm{PbSO}_{4}$ crystals, yielding a film with smaller crystals and higher crystal densities. In addition, results from experiments with and without sodium lignosulfonate indicate an increase in the nucleation rate of the $\mathrm{PbSO}_{4}$ crystals when the oxidation current is applied, which was attributed to an increase in the supersaturation of the electrolyte. Furthermore, an analysis of the growth rates of individual, large crystals showed an initial rapid growth which declined as the $\mathrm{PbSO}_{4}$ surface coverage increased. It was concluded that the increase in $\mathrm{PbSO}_{4}$ provides additional sites for precipitation and reduces the precipitation rate on the existing crystals. Finally, the potentialtime transient at the beginning of oxidation is suggested to result from the relaxation of a supersaturated solution and the development of a $\mathrm{PbSO}_{4}$ film with increasing resistance.
\end{abstract}

\title{
Keywords
}

Lead acid battery; transmission x-ray microscopy; negative electrode; expander; nucleation and growth 


\section{Introduction}

One of the major factors limiting the widespread use of lead-acid batteries for smart-grid applications (e.g., load-leveling, distribution deferral, and renewable energy storage) is a relatively short cycle life when compared to other electrochemical energy storage technologies [1]. The short cycle life can be attributed to a variety of aging processes, including: anodic corrosion, positive active mass degradation, active mass sintering, and the irreversible formation of $\mathrm{PbSO}_{4}$ on the surface of the electrodes (i.e., sulfation) [2]. The prevalence of each aging mechanism on the various components in the battery strongly depends on the operating conditions and design of the system. For one of the components, the negative electrode, one of the major life limiting factors is sulfation, which occurs when the $\mathrm{PbSO}_{4}$ film becomes irreversible and cannot be fully converted back into $\mathrm{Pb}$ after a sufficient charge [3].

For over 70 years, attempts have been made to increase the lifetime of the battery by including chemical additives in the active mass of the negative electrode [4]. Out of all the additives, wood-derived lignosulfonates (i.e., lignin) have been the most extensively studied and thorough overviews of the progress on this topic can be found in [5-7]. In recent years, further attempts to increase the lifetime have led to the development of novel chemical additives which are tailored to the specific applications of the battery. For batteries used in high-rate partial-stateof-charge applications, additions of polyaspartic acid, synthetic additive blends, and high amounts of carbon black have been shown to reduce sulfation and improve battery life [8-16]. While the results of these studies are impactful, the advances in performance typically result from trial and error testing of full-size batteries. In order to further identify methods for reducing sulfation, it would be beneficial to obtain a more fundamental understanding of the mechanisms of crystal formation, and how additives affect this process. 
One promising method for researching the mechanisms of crystal formation is the use of imaging techniques to obtain in situ observations of the growth processes. Recently, several authors have utilized atomic force microscopy (AFM) to study the effects of operating conditions (e.g., open circuit standing time and cyclic voltammetry sweep rate) and the impact of electrolyte additives on the morphology and growth rates of the $\mathrm{PbSO}_{4}$ crystals [17-23]. In these studies, the growth and reduction of $\mathrm{PbSO}_{4}$ was controlled using potentiostatic and voltammetric techniques, while the $\mathrm{PbSO}_{4}$ crystals were simultaneously visualized using AFM. Further advancement of this work would require the use of a new technique which can overcome the relatively long acquisition time (52 seconds per image) associated with the AFM. In addition, it may be beneficial to utilize constant current (galvanostatic) operating conditions, which are typically used during the testing of full-scale batteries [10-12]. Galvanostatic operating conditions would make it easier to directly relate the observations and conclusions from the microscopic, in situ work with the full-scale, macroscopic battery performance.

In our previous work, transmission X-ray microscopy (TXM), an imaging technique with a fast acquisition time (up to one second per image), was used to study the initial growth, passivation, and reduction of the $\mathrm{PbSO}_{4}$ film on $\mathrm{Pb}$ in $\mathrm{H}_{2} \mathrm{SO}_{4}$ [24]. The present study seeks to expand this work by investigating the galvanostatic growth of $\mathrm{PbSO}_{4}$ in the presence of sodium lignosulfonate, an organic macromolecule which is the precursor to many commercial chemical additives (e.g. Vanisperse A and Vanillex N). In addition, this work seeks to further understand the mechanisms of $\mathrm{PbSO}_{4}$ formation through an analysis of the growth of individual crystals, including an examination of the initial, galvanostatic potential-time transient. To accomplish this, both TXM and scanning electron microscopy (SEM) are employed.

\section{Experimental Procedure}




\subsection{TXM experiments}

The transmission X-ray microscopy (TXM) experiments were conducted using the same experimental set-up and procedure outlined in [24]. To study the impact of additives on the mechanisms of $\mathrm{PbSO}_{4}$ growth, two separate experiments were conducted: one with and one without $26 \mathrm{ppm}$ sodium lignosulfonate (i.e. lignin) added to the electrolyte. During each experiment, an electroplated $\mathrm{Pb}$ working electrode was assembled into an in-house designed, in situ, micro-electrochemical cell. The cell was placed in the transmission X-ray microscope with the $\mathrm{X}$-ray beam penetrating through the $\mathrm{Pb}$ in a direction normal to the surface. An external halfcell compartment containing a $\mathrm{Hg} \mid \mathrm{Hg}_{2} \mathrm{SO}_{4}$ reference electrode and a $\mathrm{Pt}$ counter electrode was placed outside the beam flight-path. The two compartments were connected via a tube, and the whole set-up was filled with $4.6 \mathrm{M} \mathrm{H}_{2} \mathrm{SO}_{4}$ (with and without lignin), which was deaerated for 3 hours with argon gas.

For both experiments, the electrochemical growth and reduction of the films were controlled using a BioLogic VMP3 potentiostat, which was connected to all three electrodes. Prior to each experiment, the ohmic resistance of the setup was determined using galvanostatic electrochemical impedance spectroscopy (EIS). This value was used to correct for ohmic drop between the reference and $\mathrm{Pb}$ electrodes (i.e., $\mathrm{iR}$ compensation) during the galvanostatic experiments. After the EIS, the Pb electrode was held at constant voltages of $-1.1 \mathrm{~V}$ and $-1.2 \mathrm{~V}$ for 30 minutes in order to reduce any $\mathrm{PbSO}_{4}$ that formed on the $\mathrm{Pb}$ while sitting in $\mathrm{H}_{2} \mathrm{SO}_{4}$. Next, the working electrode was held at the open-circuit voltage (OCV) for 2 minutes, followed by a galvanostatic oxidation at $50 \mu \mathrm{A} \mathrm{cm} \mathrm{cm}^{-2}$ with a cut-off voltage of $-0.84 \mathrm{~V}$ (before correcting for ohmic drop). 
The in situ transmission X-ray microscopy (TXM) was done at the X8C beamline of the National Synchrotron Light Source at Brookhaven National Laboratory. Imaging was performed at a X-ray energy of $8 \mathrm{keV}$ with a $40 \times 40 \mu \mathrm{m}\left(1600 \mu \mathrm{m}^{2}\right)$ field of view and an exposure time of 20 seconds for each image. The moderate exposure time made it possible to generate a clear image by binning a $2 \times 2$ pixel region using the $2 \mathrm{k} \times 2 \mathrm{k}$ CCD camera, resulting in a pixel size of $39 \mathrm{~nm}$ [25]. Images collected from both TXM experiments were processed using a pixel-by-pixel normalization with five background images taken from the corresponding $\mathrm{Pb}$ sample. In addition, all images in this work underwent further refinement using ImageJ software in order to better visualize the nucleation and growth of the $\mathrm{PbSO}_{4}$ films. A more detailed description of the image refinement procedure can be found in [24].

\subsection{Experiments for SEM images}

Additional electrochemical experiments with and without $26 \mathrm{ppm}$ lignin in the electrolyte were performed in order to support the TXM results. $\mathrm{Pb}$ electrodes were formed by electroplating a $10-\mu \mathrm{m}$ thick layer of lead unto a $38-\mu \mathrm{m}$ thick copper substrate using the same plating procedure outlined in [24]. Prior to plating, the substrate was rinsed with isopropyl alcohol and de-ionized water. After plating, the electrode was rinsed with de-ionized water and dried with argon gas. The electrochemically active area of the $\mathrm{Pb}\left(\sim 0.1 \mathrm{~cm}^{2}\right)$ was defined by melting paraffin wax onto the sample. The exact active area for each sample was obtained by analyzing an image of the electrode using the area selection tools available in the ImageJ software [26]. The electrochemical experiments were conducted using a three-electrode system with a $\mathrm{Hg} \mid \mathrm{Hg}_{2} \mathrm{SO}_{4}$ reference electrode and a Pt counter electrode. All three electrodes were placed in a beaker containing $70 \mathrm{~mL}$ of $4.6 \mathrm{M} \mathrm{H}_{2} \mathrm{SO}_{4}$ (with and without $26 \mathrm{ppm}$ lignin), which 
was deaerated for 3 hours with argon gas. The entire beaker was blanketed with argon gas for 15 minutes and then sealed with paraffin wax for the entirety of the experiment.

The electrochemical experiments were controlled using a $\mu$ AutolabIII potentiostat (Metrohm USA, Inc.). The $\mathrm{Pb}$ electrode was first held at a constant voltage of $-1.1 \mathrm{~V}$ for 30 minutes in an attempt to reduce any $\mathrm{PbSO}_{4}$ that formed on the $\mathrm{Pb}$ while sitting in $\mathrm{H}_{2} \mathrm{SO}_{4}$. Next, the working electrode was held at the open-circuit voltage for 2 minutes, followed by a galvanostatic oxidation at $50 \mu \mathrm{A} \mathrm{cm}{ }^{-2}$. The end of the oxidation was either specified by a given amount of time (e.g., 1 minute) or by allowing the electrode to passivate using a cutoff voltage of $-0.85 \mathrm{~V}$. Immediately after the oxidation, the sample was removed from the acid, rinsed with deionized water, and dried with argon gas. Scanning electron microscope (SEM) images were taken of the sample surface using a Hitachi 4700 microscope. A minimum of three regions was imaged for each sample.

\section{Results and Discussion}

\subsection{Comparison of TXM and SEM images}

In order to aid in the interpretation of the results from the TXM experiments, the images obtained from the TXM were compared to SEM images taken from separate experiments. Figures 1 and 2 show a comparison of TXM and SEM images of the $\mathrm{PbSO}_{4}$ films grown with and without lignin in the electrolyte, respectively. Included in both figures are images taken 3 minutes after the start of the OCV procedure (images a1 and b1) and at passivation of the electrode (images a2 and b2). Good agreement is observed between the SEM and TXM images, especially for the images taken 3 minutes after the start of OCV (images a1 and b1) and for the experiments conducted with $26 \mathrm{ppm}$ lignin in the electrolyte (Figure 2). In Fig. 2, both the TXM and SEM images at passivation (Fig. 2, images a2 and b2) depict a film containing a few, large 
crystals dispersed among many, smaller, $\mathrm{PbSO}_{4}$ crystallites. In contrast, the SEM image taken at passivation from the experiment without lignin in the electrolyte (Fig. 1, image b2) shows a film containing many, large, overlapping crystals. It appears that these overlapping crystals were difficult to deconvolute using transmission X-rays (Fig. 1, image a2), resulting in an image without clearly defined crystallites.

(Insert Figures 1 and 2 here)

\subsection{Impact of lignin on $\mathrm{PbSO}_{4}$ morphology and growth}

\subsubsection{Oxidation until passivation}

The voltage responses of the open circuit voltage (OCV) and galvanostatic oxidation steps of the TXM experiments conducted with and without 26 ppm lignin are shown in Figure 3. All times in the remaining figures throughout the paper are reported in reference to this figure. The results show that addition of lignin to the electrolyte decreased the time to passivation in the experiment by $\sim 15 \%$; whereby passivation is indicated by the sudden increase in voltage. The decrease in passivation time caused by lignin can be attributed to the morphological differences in the $\mathrm{PbSO}_{4}$ films. When comparing the two films at passivation, the SEM images (images b2 in Figures 1 and 2) indicate that the film formed with lignin in the electrolyte contains higher amounts of small crystals. High amounts of small crystals result in a more densely packed morphology when the film is relatively thin. The thin, dense film blocks the diffusion of reactants, passivating the electrode with minimal $\mathrm{PbSO}_{4}$. A similar observation was made by Hampson and Lakeman, who conducted potentiostatic oxidations on $\mathrm{Pb}$ at various potentials and recorded the charge required for passivation [27]. They also concluded that films with a higher crystal density and a smaller average crystal size resulted in a quicker passivation and a smaller capacity. 


\section{(Insert Figure 3 here)}

The observed decrease in passivation time contradicts the fact that lignin is known to increase the capacity of the negative electrode in a lead acid battery [4-6, 12, 28-32]. Currently, two main mechanisms have been proposed to explain why lignin increases the capacity, neither of which is expected to be a major factor in this study. First, lignin is known to increase the capacity during the forming of the electrode by producing a high porosity, high surface area structure, which improves utilization of the active mass $[4,12,31,32]$. In the present study, these beneficial effects are not expected to occur because electroplated $\mathrm{Pb}$ was used, which did not undergo an electrode formation process. In the second mechanism, lignin in the electrolyte adsorbs onto the $\mathrm{Pb}$ surface, which causes the $\mathrm{PbSO}_{4}$ to precipitate on top of the lignin instead of directly onto the $\mathrm{Pb}$. This results in the formation of a more porous $\mathrm{PbSO}_{4}$ film, which improves the capacity by leaving the active $\mathrm{Pb}$ available for further $\mathrm{Pb}^{2+}$ dissolution $[5,6,28-30]$. Before lignin can adsorb onto the $\mathrm{Pb}$ surface, it must first complex with $\mathrm{Pb}^{2+}$ ions in the solution to make an insoluble molecule [33]. In the present study, the potentiostatic reductions performed at the beginning of the experiment reduced any free $\mathrm{Pb}^{2+}$ ions. Therefore, the lignin was unable to complex and adsorb onto the $\mathrm{Pb}$ at the onset of the experiment. Without an initial layer of adsorbed lignin on the $\mathrm{Pb}$ surface, the beneficial effects on the $\mathrm{PbSO}_{4}$ film are reduced and no increase in capacity is observed.

\subsubsection{Crystal size distributions}

In order to determine the mechanism by which lignin changes the morphology of the $\mathrm{PbSO}_{4}$ film and decreases the capacity in this study, distributions of the crystal sizes at various times during the TXM experiments were obtained by analyzing the TXM images with ImageJ software. The size of each crystal was calculated by determining the maximum length of a 
straight line which could be drawn from one end of the crystal to another. The measurement represents the diameter for non-spherical particles.

Figures 4 and 5 show the crystal size distributions obtained from the TXM and SEM experiments without and with lignin in the electrolyte, respectively. In addition, the mean, median, and mode of the distributions obtained from the TXM experiments are shown in Figure 6. For each histogram bar in Figures 4 and 5, the crystal size on the horizontal axis corresponds to the center of the bin. The distributions of the crystals from the TXM experiments (Figures 4a and 5a) were normalized based on the total amount of crystals at $t=160$ seconds. After this time, distributions were unattainable due to overlapping of crystals in the films, which obscured determination of individual sizes (image a1 of Figures 1 and 2). Each SEM crystal distribution (Figures $4 \mathrm{~b}$ and $5 \mathrm{~b}$ ) was obtained from three separate images of the same sample and was normalized with respect to the total number of crystals used in the study. An example image for each experiment is shown in image b1 of Figures 1 and 2. The TXM data show good agreement with the distributions obtained from the SEM images.

\section{(Insert Figures 4, 5 and 6 here)}

The mechanism of action of the lignin can be revealed from an analysis of the crystal distributions. For instance, Figures $4 \mathrm{a}$ and $6 \mathrm{a}$ show that the number and average size of the crystals increases during the early growth of the film without lignin. This behavior corresponds to a progressive nucleation and growth mechanism, where new crystals are continually forming, and pre-existing crystals are continually growing. In contrast, Figures $5 \mathrm{a}$ and $6 \mathrm{~b}$ show that in the presence of lignin the number of crystals increases while the size distribution remains relatively the same. This trajectory in morphology indicates that lignin retards the growth of the crystals. Myrvold has shown that lignin will quickly adsorb onto $\mathrm{PbSO}_{4}$, and it appears that this 

precipitation of $\mathrm{Pb}(\mathrm{II})$ species from the electrolyte, the adsorbed lignin most likely prevents the growth by physically blocking the precipitation sites on the crystals [34].

\subsubsection{Crystal density and surface coverage}

Because lignin impedes the growth of the existing $\mathrm{PbSO}_{4}$, it is anticipated that the number of crystals will increase in the presence of lignin in order to provide enough precipitation sites for the $\mathrm{Pb}$ (II) species. This hypothesis is verified in Figure 7, which shows $\mathrm{PbSO}_{4}$ crystal densities for the images obtained from the TXM and SEM experiments. Each crystal density was determined by manually counting the number of crystals using ImageJ software and dividing that number by the area of the image. Similar to the crystal size distributions in Figures 4 and 5 , the crystal densities for TXM images after $t=160$ seconds were unattainable due to the overlapping of crystals and the coalescing of the films (images a1 of Figures 1 and 2). The data points for the SEM experiments were determined from the averages of three separate images of the same sample. The error bars represent the maximum and minimum values obtained from the sample. An example image for each SEM experiment is shown in image b1 of Figures 1 and 2.

In Fig. 7a, the experiments without lignin show good agreement between the TXM and SEM data. Extrapolation of the TXM data to $t=180$ seconds results in a crystal density of $\sim 80 \times$ $10^{6} \mathrm{~cm}^{-2}$, which is only 1.1 times higher than the average crystal density reported for the SEM experiments $\left(\sim 70 \times 10^{6} \mathrm{~cm}^{-2}\right)$. For the experiments with lignin, there is less of an agreement between the TXM and SEM data. Extrapolation of the TXM data results in a crystal density of $\sim 90 \times 10^{6} \mathrm{~cm}^{-2}$, which is 1.3 times smaller than the average crystal density obtained from the SEM images $\left(\sim 120 \times 10^{6} \mathrm{~cm}^{-2}\right)$. Despite this discrepancy, the TXM extrapolation for the experiment with lignin still resides within the error bars of the SEM data. 
(Insert Figure 7 here)

Figure $7 \mathrm{~b}$ shows the crystal densities for the TXM experiments. The results further confirm that lignin increases the crystal density. In addition, Fig. $7 \mathrm{~b}$ shows that the rate of crystal nucleation approximately doubles in both experiments when the oxidation current is applied. The increase in crystal nucleation rate can be attributed to an increase in the oxidation

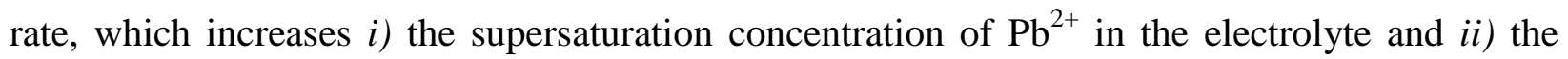
overpotential. Both of these factors decrease the critical nucleus size, which increases the rate of nucleation [35].

The supersaturation can increase when the current is applied because the oxidation rate exceeds that at $\mathrm{OCV}$. For this system, the oxidation of $\mathrm{Pb}$ at $\mathrm{OCV}$ is balanced by the following proton reduction reaction:

$$
2 \mathrm{H}^{+}+2 e^{-} \rightarrow \mathrm{H}_{2}, \quad \mathrm{E}^{0}=-0.587 \text { V vs. } \mathrm{Hg} \mid \mathrm{Hg}_{2} \mathrm{SO}_{4}
$$

When the current is applied, the proton reduction rate decreases due to the increase in the electrode potential. The change in the proton reduction rate can be determined by performing a Taylor series expansion of the Tafel equation. This results in the following:

$$
\Delta i=\frac{\left|i_{c o r r}\right| \alpha_{c} F}{R T} \Delta \phi
$$

where $\alpha_{c}$ is the cathodic charge transfer coefficient $\left(\alpha_{c}=0.5\right), R$ is the ideal gas constant, $T$ is the temperature, $F$ is Faraday's constant, and $\Delta \phi$ is the change in potential applied to the electrode. $\Delta \phi$ is $\sim 20 \mathrm{mV}$ at the beginning of oxidation (Figures 3 and 12). $i_{\text {corr }}$ is the steady state corrosion rate, which for this system is $50 \mu \mathrm{A} \mathrm{cm}^{-2}$. [24]. According to Eq. 4, $\Delta i$ is equal to $+20 \mu \mathrm{A} \mathrm{cm}^{-2}$ at the beginning of oxidation, indicating that the reduction rate changes from -50 
$\mu \mathrm{A} \mathrm{cm}{ }^{-2}$ at $\mathrm{OCV}$ to $-30 \mu \mathrm{A} \mathrm{cm} \mathrm{cm}^{-2}$ when the current is applied. Therefore, in order for the applied current to reach $50 \mu \mathrm{A} \mathrm{cm}^{-2}$, the actual oxidation rate can be estimated to be $\sim 80 \mu \mathrm{A} \mathrm{cm}{ }^{-2}$, which is $~ 1.6$ times higher than expected from the applied current.

To further understand the mechanism of growth of the $\mathrm{PbSO}_{4}$ crystals, the surface coverage vs. time and overpotential vs. surface coverage are plotted in Figure 8. Fig. 8a indicates that the electrode is fully covered with $\mathrm{PbSO}_{4}$ within the first 3 to 5 minutes of oxidation. The remainder of the oxidation corresponds to a thickening of the film [24]. In addition, both experiments (without and with lignin) have similar trends in overpotential (Fig. 8b), suggesting a similar mechanism of growth. The higher overpotential observed for the experiment with lignin can be attributed to the retardation in growth of the crystals. The trends in overpotential resemble the analytical expressions derived by Hills et. al. for the two dimensional growth of cylindrical crystals under galvanostatic conditions [36]. However, a rigorous analysis of the data to distinguish between instantaneous and progressive nucleation was not possible due to the scatter of the TXM results.

(Insert Figure 8 here)

\subsection{Growth of individual crystals}

In Section 3.2.2, trends in crystal size obtained from the TXM images illustrated how lignin impacted the morphology of the $\mathrm{PbSO}_{4}$. Although useful, the analysis cannot be applied to individual particles because size distributions (i.e., mean, median, and mode) are heavily influenced by the continued nucleation of new crystals. In this section, we use TXM to track the evolution of individual $\mathrm{PbSO}_{4}$ crystals. A select group of crystals from the experiments without and with lignin were identified whose growth evolution was visualized by the TXM. Due to the 
need to easily visualize the crystals, the selected crystals tended to be the largest in the films. They are highlighted in images b1 and b2 of Figure 9.

\section{(Insert Figure 9 here)}

In Figure 9, graphs a1 and a2 track the increase in area of the crystals (i.e., the projections on the substrate) during the early stages of growth. For each crystal, the two-dimensional projections could not be tracked past $t=340$ seconds due to crystal overlap and coalescence of the films. The crystals with and without lignin appear to have a similar growth pattern. Both sets of crystals appear to grow in two stages. In the first stage, the crystal area increases rapidly during the initial 50 to 150 seconds of growth. After this period, the growth rates appear to slow, signifying the second stage. This trend is most noticeable for crystals a, c, and $\mathrm{d}$ in the experiment without lignin and for crystals 1, 3, and 6 in the experiment with lignin. Note that the transition between the rapid and slow stages of growth occurs between $t=140$ seconds and $t=$ 180 seconds for these crystals. This is close to the time ( $t=180$ seconds) when the crystal sizes and crystal densities could no longer be determined in Figures 4a, 5a, and 7 due to coalescence of the film. It suggests that the decrease in growth rate from the first to the second stage may be attributed to an increase in the surface coverage of the $\mathrm{PbSO}_{4}$. An increase in $\mathrm{PbSO}_{4}$ increases the available precipitation sites and causes overlap between the diffusion zones of individual crystals. Both of these factors limit the amount of precipitation on the existing crystals [37].

\section{(Insert Figure 10 here)}

To highlight the two observed stages of growth, Figure 10 shows magnified TXM images of crystals 3 and 6 in image b2 of Fig. 9. In order to aid in the interpretation of this figure, these crystals can be compared to the crystals in the SEM image shown in the magnified portion of image b1 in Fig. 2. The crystal on the right in Fig. 10 (crystal 6) resembles a thin, flat crystal that 
appears to be growing in a planar direction along the surface of the Pb electrode. Meanwhile, the crystal on the left (crystal 3) more closely resembles a thin crystal growing in both the normal and planar directions.

Referring back to Fig. 10, during the first stage of growth (up to $t=\sim 160$ seconds), the two white $\mathrm{PbSO}_{4}$ crystals appear to grow rapidly on the predominantly black $\mathrm{Pb}$ background. Based on the SEM comparison, the crystals are thin and flat. For the crystals to have this structure, their growth is likely two-dimensional. After $t=\sim 160$ seconds, additional small, white, $\mathrm{PbSO}_{4}$ crystals become visible, especially around the crystal on the left (crystal 3). These times correspond well to the slowing of the growth rates observed in Fig. 9, further suggesting that the slowdown in growth during the second stage is due to the presence of other crystals on the surface. Although crystal growth slows in the planar direction during the second stage, the SEM images in Fig. 2 suggest that crystal growth increases in the normal direction. For instance, a comparison of SEM images b1 and b2 in Fig. 2 shows that the large crystals at passivation (image b2) contain a more three-dimensional, pyramidal structure than the large crystals at the beginning of oxidation (image b1). In order for the large crystals in image b2 to have grown from large crystals similar to those in image b1, their growth in the normal direction would have to be greater-than-or-equal to their growth in the other two dimensions.

\section{(Insert Figure 11 here)}

To further investigate the growth processes of the crystals, the projected area of each crystal was plotted versus time on a logarithmic plot. These graphs are shown in Figure 11. For both experiments (without and with lignin), no clear power-law dependence $\left(A \propto t^{n}\right)$ is observed. This suggests that the growth mechanism is complex and cannot be explained by a simple diffusion-limited or kinetics-limited growth model. 


\subsection{Explanation for the voltage dip}

An analysis of the early formation of $\mathrm{PbSO}_{4}$ on $\mathrm{Pb}$ in $\mathrm{H}_{2} \mathrm{SO}_{4}$ may also provide insight into the potential-time transient behavior at the beginning of oxidation. Specifically, the anodic overpotential initially decreases, goes through a minimum, and then begins to increase. [38]. In a lead acid battery, a similar behavior, termed the coup de fouet, is observed at the beginning of discharge, but it is attributed to the positive electrode, where $\mathrm{PbO}_{2}$ is reduced to $\mathrm{PbSO}_{4}$ [39]. Similar phenomena occur at the negative electrode, where $\mathrm{Pb}$ is oxidized to $\mathrm{PbSO}_{4}$, but it is of smaller magnitude.

\section{(Insert Figure 12 here)}

The transient at the start of oxidation in the TXM experiments is shown in Figure 12. The initial increase in overpotential likely corresponds to an increase in i) the double layer capacitance of the electrode and ii) the supersaturation of the solution with $\mathrm{Pb}^{2+}$ ions. The supersaturation provides a driving force for crystallization and may be written as a concentration overpotential $\left(\eta_{c}\right)[34]$ :

$$
\eta_{c}=\frac{R T}{2 F} \ln \left(\frac{c_{P b^{2+}}}{c_{P b^{2+}}^{e}}\right)
$$

where $c_{\mathrm{Pb}^{2+}}$ is the $\mathrm{Pb}^{2+}$ concentration in the solution, and $c_{\mathrm{Pb}^{2+}}^{e}$ is the saturated $\mathrm{Pb}^{2+}$ concentration at equilibrium. Based on this equation, the decrease in overpotential from the initial spike to the plateau voltage is due to a relaxation in $c_{P b^{2+}}$ back to the equilibrium value. The relaxation in $c_{\mathrm{Pb}^{2+}}$ can be related to the increase in the surface coverage of $\mathrm{PbSO}_{4}$ on the electrode (Fig. 8). For instance, the increase in surface coverage increases the number of available sites for precipitation of $\mathrm{Pb}^{2+}$ species. This increases the precipitation rate of $\mathrm{Pb}^{2+}$, 
which causes $c_{\mathrm{Pb}^{2+}}\left(\right.$ and $\left.\eta_{c}\right)$ to decrease. This analysis implies that the rate of $\mathrm{Pb}^{2+}$ dissolution, which is equal to the applied current, may not equal the rate of $\mathrm{PbSO}_{4}$ precipitation. This agrees with the explanation provided by Bernardi for the coup de fouet at the positive electrode [40].

In addition to the relaxation of the supersaturated concentration, the plateau voltage may correspond to the coalescence of the $\mathrm{PbSO}_{4}$ film. For instance, Figure 12 highlights the occurrence of three specific events during the formation of the film. All three events occur close to the time when the plateau voltage is reached. The first mark at $t=160$ seconds corresponds to the time when the crystal size distributions in Figures 4 and 5 and the crystal densities in Fig. 7 were unattainable due to overlapping of the crystals. The second mark signifies the region where the growth of the crystals in Fig. 9 began to slow due to the presence of other crystals on the surface. Finally, the third mark corresponds to the time when the film is fully coalesced [24].

\section{Conclusions}

This study examined the effects of an organic additive on $\mathrm{PbSO}_{4}$ growth and analyzed the early growth mechanisms of $\mathrm{PbSO}_{4}$. Addition of sodium lignosulfonate to the $\mathrm{H}_{2} \mathrm{SO}_{4}$ was shown to impede, on average, the growth of the $\mathrm{PbSO}_{4}$ crystals, which resulted in a $\mathrm{PbSO}_{4}$ film with smaller crystals and an increased crystal density. For experiments with and without lignin, an increase in the crystal nucleation rate was observed when the oxidation current was applied. This was attributed to an increase in the supersaturation of the electrolyte. In addition, the early growth of the large $\mathrm{PbSO}_{4}$ crystals was examined with and without lignin. For both cases, there was an initial, rapid growth rate, which declined after 50 to 150 seconds. The decline in growth rate was attributed to an increase in the $\mathrm{PbSO}_{4}$ coverage, which increased the number of precipitation sites competing for $\mathrm{PbSO}_{4}$. Finally, the potential-time transient at the beginning of 
oxidation was suggested to result from the relaxation of a supersaturated solution and the development of $\mathrm{PbSO}_{4}$ film with increasing resistance.

\title{
Acknowledgements
}

\author{
K. W. K. greatly acknowledges the support of the National Science Foundation Graduate \\ Research Fellowship under Grant No. 1144155. Any opinions, findings, and conclusions or \\ recommendations expressed in this material are those of the authors and do not necessarily \\ reflect the views of the National Science Foundation. \\ This work was supported in part by the American Recovery and Reinvestment Act \\ funding through Department of Energy, Office of Science, Office of Basic Energy Sciences. Use \\ of the National Synchrotron Light Source, Brookhaven National Laboratory for this work was \\ supported by the U.S. Department of Energy, Office of Science, Office of Basic Energy Sciences \\ under Contract No. DE-AC02-98CH10886.
}




\section{References}

[1] H.S. Chen, T.N. Cong, W. Yang, C.Q. Tan, Y.L. Li, Y.L. Ding, Progress in electrical energy storage system: A critical review, Prog. Nat. Sci., 19 (2009) 291-312.

[2] P. Ruetschi, Aging mechanisms and service life of lead-acid batteries, J. Power Sources, 127 (2004) 33-44.

[3] D.U. Sauer, Secondary Batteries - Lead-acid systems | Lifetime determining processes, in: J. Garche (Ed.) Encyclopedia of Electrochemical Power Sources, Elsevier, Amsterdam, 2009, pp. 805-815.

[4] E.J. Ritchie, Addition agents for negative plates of lead-acid storage batteries 1. Introductory, Trans. Electrochem. Soc., 92 (1947) 229-257.

[5] G.J. Szava, Role of the organic expander in modern lead/acid batteries, J. Power Sources, 23 (1988) 119-124.

[6] G.I. Aidman, A view on chemically synthesized expanders for lead/acid battery negative plates, J. Power Sources, 59 (1996) 25-30.

[7] D. Pavlov, P. Nikolov, T. Rogachev, Influence of expander components on the processes at the negative plates of lead-acid cells on high-rate partial-state-of-charge cycling. Part I: Effect of lignosulfonates and $\mathrm{BaSO} 4$ on the processes of charge and discharge of negative plates, J. Power Sources, 195 (2010) 4435-4443.

[8] D. Pavlov, P. Nikolov, Lead-carbon electrode with inhibitor of sulfation for lead-acid batteries operating in the HRPSoC duty, J. Electrochem. Soc., 159 (2012) A1215-A1225.

[9] C. Francia, M. Maja, P. Spinelli, F. Saez, B. Martinez, D. Marin, Electrochemical techniques for the characterisation of expander materials, J. Power Sources, 85 (2000) 102-109.

[10] D. Pavlov, B.O. Myrvold, T. Rogachev, M. Matrakova, A new generation of highly efficient expander products and correlation between their chemical composition and the performance of the lead-acid battery, J. Power Sources, 85 (2000) 79-91.

[11] F. Saez, B. Martinez, D. Marin, P. Spinelli, F. Trinidad, The influence of different negative expanders on the performance of VRLA single cells, J. Power Sources, 95 (2001) 174-190.

[12] D.P. Boden, J. Arias, F.A. Fleming, The effect of organic expander materials on the performance, life, surface area and crystal structure of negative electrodes in valve regulated cells, J. Power Sources, 95 (2001) 277-292.

[13] J. Valenciano, F. Trinidad, M. Fernandez, The influence of different negative expanders on the performance of VRLA batteries, J. Power Sources, 113 (2003) 318-328.

[14] P.T. Moseley, R.F. Nelson, A.F. Hollenkamp, The role of carbon in valve-regulated leadacid battery technology, J. Power Sources, 157 (2006) 3-10.

[15] M. Calabek, K. Micka, P. Krivik, P. Baca, Significance of carbon additive in negative leadacid battery electrodes, J. Power Sources, 158 (2006) 864-867.

[16] D.P. Boden, D.V. Loosemore, M.A. Spence, T.D. Wojcinski, Optimization studies of carbon additives to negative active material for the purpose of extending the life of VRLA batteries in high-rate partial-state-of-charge operation, J. Power Sources, 195 (2010) 4470-4493. [17] Y. Yamaguchi, M. Shiota, Y. Nakayama, N. Hirai, S. Hara, In situ analysis of electrochemical reactions at a lead surface in sulfuric acid solution, J. Power Sources, 85 (2000) 22-28.

[18] Y. Yamaguchi, M. Shiota, M. Hosokawa, Y. Nakayama, N. Hirai, S. Hara, Study of charge acceptance for the lead-acid battery through in situ EC-AFM observation - influence of the opencircuit standing time on the negative electrode, J. Power Sources, 102 (2001) 155-161. 

CV measurement study on lead electrode for lead-acid batteries, J. Power Sources, 93 (2001) 104-111.

[20] I. Ban, Y. Yamaguchi, Y. Nakayama, N. Hirai, S. Hara, In situ EC-AFM study of effect of lignin on performance of negative electrodes in lead-acid batteries, J. Power Sources, 107 (2002) 167-172.

[21] H. Vermesan, N. Hirai, M. Shiota, T. Tanaka, Effect of barium sulfate and strontium sulfate on charging and discharging of the negative electrode in a lead-acid battery, J. Power Sources, 133 (2004) 52-58.

[22] N. Hirai, D. Tabayashi, M. Shiota, T. Tanaka, In situ electrochemical atomic force microscopy of lead electrodes in sulfuric acid solution with or without lignin during anodic oxidation and cathodic reduction, J. Power Sources, 133 (2004) 32-38.

[23] N. Hirai, S. Kubo, K. Magara, Combined cyclic voltammetry and in situ electrochemical atomic force microscopy on lead electrode in sulfuric acid solution with or without lignosulfonate, J. Power Sources, 191 (2009) 97-102.

[24] K.W. Knehr, C. Eng, Y. K. Chen-Wiegart, J. Wang, A.C. West, In situ transmission X-ray microscopy of the lead sulfate film formation on lead in sulfuric acid, J. Electrochem. Soc., 162 (2015) A255-A261.

[25] J. Wang, Y.C.K. Chen, Q.X. Yuan, A. Tkachuk, C. Erdonmez, B. Hornberger, M. Feser, Automated markerless full field hard x-ray microscopic tomography at sub-50 nm 3-dimension spatial resolution, Appl. Phys. Lett., 100 (2012) 143107.

[26] T. Ferreira, W.S. Rasband, ImageJ User Guide - IJ 1.46, 2010-2012.

[27] N.A. Hampson, J.B. Lakeman, The effect of potential on the surface structure of lead electrodes in sulphuric acid in the anodic region, Surf. Technol., 9 (1979) 97-102.

[28] M.P.J. Brennan, N.A. Hampson, Expander action in the lead-acid battery 1. Effects upon the mechanism of the oxidation process, J. Electroanal. Chem., 48 (1973) 465-474.

[29] A.C. Simon, S.M. Caulder, P.J. Gurlusky, J.R. Pierson, The effect of additives on the reaction-mechanism of the $\mathrm{Pb} / \mathrm{PbSO} 4$ electrode, J. Electrochem. Soc., 121 (1974) 463-467.

[30] B.K. Mahato, Lead-acid battery expander 1. Electrochemical evaluation techniques, J. Electrochem. Soc., 127 (1980) 1679-1687.

[31] J.R. Pierson, P. Gurlusky, A.C. Simon, S.M. Caulder, Crystallogenic modification in the formation process at the lead electrode by the addition of a lignin derivative, J. Electrochem. Soc., 117 (1970) 1463-1470.

[32] A.C. Simon, S.M. Caulder, P.J. Gurlusky, J.R. Pierson, The structure of the Pb/PbSO4 electrode in the reduced state and the changes produced by lignin derivatives and BaSO4, Electrochim. Acta, 19 (1974) 739-743.

[33] B.O. Myrvold, Interactions between lignosulphonates and the components of the lead-acid battery Part 1. Adsorption isotherms, J. Power Sources, 117 (2003) 187-202.

[34] L.M. Baugh, K.L. Bladen, F.L. Tye, Aspects of the electrochemistry of lead in acid media Part III. Active dissolution and the active-passive transition in oxygenated and deoxygenated sulphuric acid solutions, J. Electroanal. Chem., 145 (1983) 355-377.

[35] A. Milchev, M.I. Montenegro, A galvanostatic study of electrochemical nucleation, J. Electroanal. Chem., 333 (1992) 93-102.

[36] G.J. Hills, L.M. Peter, B.R. Scharifker, M.I.D. Pereira, The Nucleation and growth of twodimensional anodic films under galvanostatic conditions, J. Electroanal. Chem., 124 (1981) 247262. 
[37] B. Scharifker, G. Hills, Theoretical and experimental studies of multiple nucleation, Electrochim. Acta, 28 (1983) 879-889.

[38] M. Perrin, A. Delaille, Secondary batteries - Lead-acid systems | Coup de fouet, in: J. Garche (Ed.) Encyclopedia of Electrochemical Power Sources, Elsevier, Amsterdam, 2009, pp. 779-792.

[39] A. Delaille, M. Perrin, F. Huet, L. Hernout, Study of the "coup de fouet" of lead-acid cells as a function of their state-of-charge and state-of-health, J. Power Sources, 158 (2006) 10191028.

[40] D.M. Bernardi, Nucleation of lead sulfate in porous lead-dioxide electrodes, J. Electrochem. Soc., 137 (1990) 1670-1681. 


\section{List of Figures}

Figure 1. a) TXM and b) SEM images taken during oxidation of $\mathrm{Pb}$ at $50 \mu \mathrm{A} \mathrm{cm} \mathrm{cm}^{-2}$ in $4.6 \mathrm{M}$ $\mathrm{H}_{2} \mathrm{SO}_{4}$ : 1) 3 minutes after the start of OCV (see Fig. 3); 2) passivation with $\mathrm{PbSO}_{4}$.

Figure 2. a) TXM and b) SEM images taken during oxidation of $\mathrm{Pb}$ at $50 \mu \mathrm{A} \mathrm{cm} \mathrm{cm}^{-2}$ in $4.6 \mathrm{M}$ $\mathrm{H}_{2} \mathrm{SO}_{4}$ with 26 ppm sodium lignosulfonate: 1) 3 minutes after the start of OCV (see Fig. 3); 2) passivation with $\mathrm{PbSO}_{4}$.

Figure 3. Voltage response of TXM experiments without and with $26 \mathrm{ppm}$ sodium lignosulfonate added to the electrolyte. For both, $\mathrm{Pb}$ electrode was held at open-circuit voltage for 2 minutes, followed by a galvanostatic oxidation at $50 \mu \mathrm{A} \mathrm{cm}^{-2}(-0.87 \mathrm{~V}$ cutoff).

Figure 4. Distribution of crystal sizes for $\mathrm{PbSO}_{4}$ grown on $\mathrm{Pb}$ in $4.6 \mathrm{M} \mathrm{H}_{2} \mathrm{SO}_{4}$ : a) TXM experiment, b) separate experiment on electroplated $\mathrm{Pb}$. Time in figures is in reference to the start of OCV (Fig. 3).

Figure 5. Distribution of crystal sizes for $\mathrm{PbSO}_{4}$ grown on $\mathrm{Pb}$ in $4.6 \mathrm{M} \mathrm{H}_{2} \mathrm{SO}_{4}$ with 26 ppm sodium lignosulfonate: a) TXM experiment, b) separate experiment on electroplated $\mathrm{Pb}$. Time in figures is in reference to the start of OCV (Fig. 3).

Figure 6. Mean, median, and mode of the crystal sizes obtained from the TXM experiments a) without and b) with 26 ppm sodium lignosulfonate in the electrolyte.

Figure 7. $\mathrm{PbSO}_{4}$ crystal density on $\mathrm{Pb}$ in $4.6 \mathrm{M} \mathrm{H}_{2} \mathrm{SO}_{4}$ without and with 26 ppm sodium lignosulfonate. a) Comparison of SEM and TXM data. Error bars on SEM data indicate maximum and minimum values observed from multiple images of the same sample. b) Close-up of TXM data. Slopes of fits have units $\left[\mathrm{x} 10^{6} \mathrm{~cm}^{-2} \mathrm{~s}^{-1}\right]$.

Figure 8. a) $\mathrm{PbSO}_{4}$ surface coverage vs. time during the OCV and galvanostatic experiments. b) Overpotential vs. surface coverage during the oxidation experiment. 
Figure 9. a) Initial increase in the projected area for a select group of crystals. b) TXM image of crystals used in study at $\mathrm{t}=180$ seconds. Results are from experiments 1) without and 2) with 26 ppm sodium lignosulfonate in the electrolyte.

Figure 10. TXM images of crystals 3 and 6 (Fig. 9, image b2) grown at $50 \mu \mathrm{A} \mathrm{cm}^{-2}$. Times are in reference to the start of OCV (Fig. 3).

Figure 11. Logarithmic plots of crystal area vs. time for the projections of individual crystals in experiments a) without and b) with 26 ppm sodium lignosulfonate in the electrolyte.

Figure 12. Initial voltage response of galvanostatic oxidation at $50 \mu \mathrm{A} \mathrm{cm}{ }^{-2}$ in TXM set-up for experiment without and with $26 \mathrm{ppm}$ sodium lignosulfonate in the electrolyte. I, II, and III mark the occurrence of specific events during the film growth. 

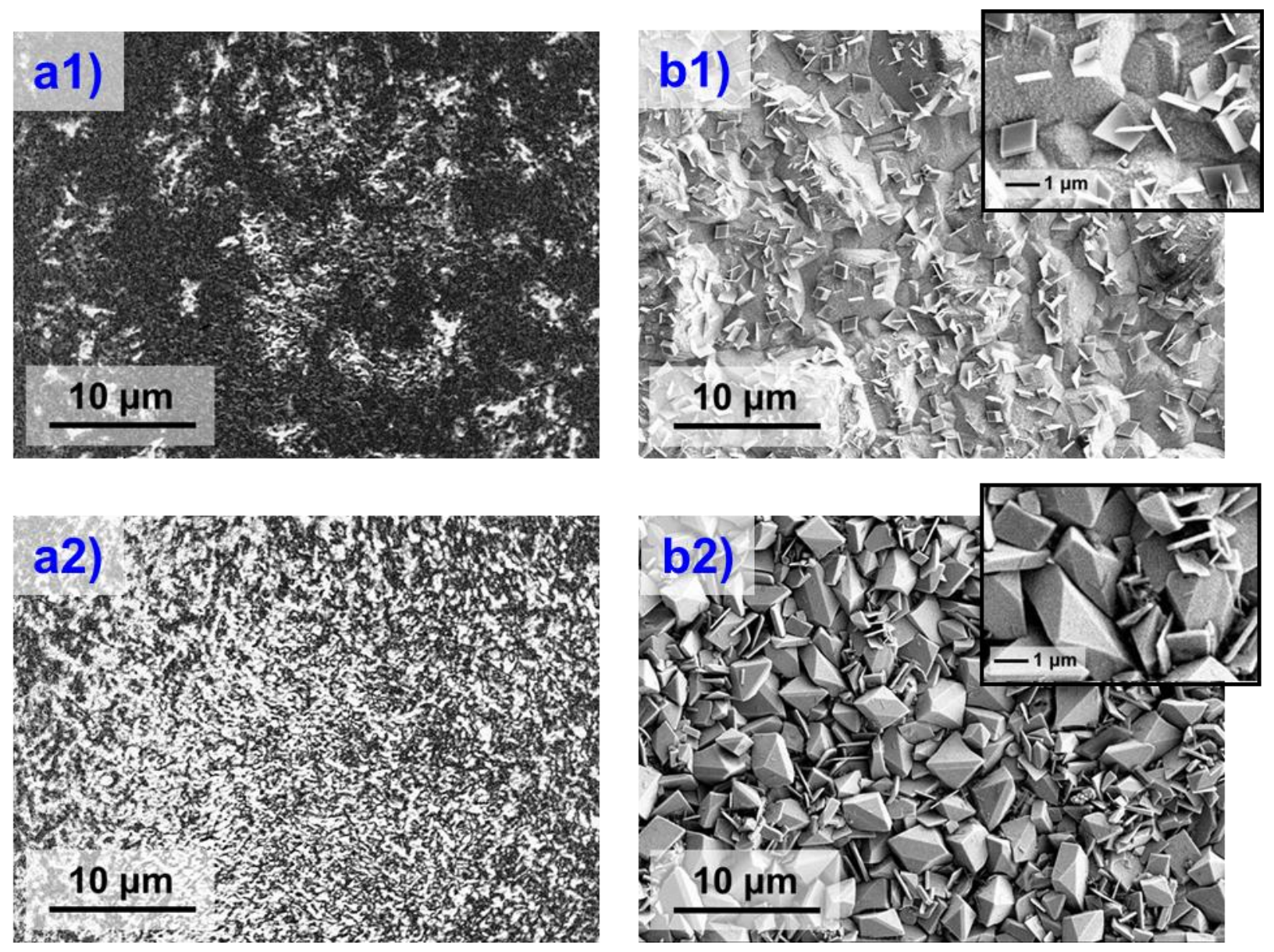

Figure 1. a) TXM and b) SEM images taken during oxidation of $\mathrm{Pb}$ at $50 \mu \mathrm{A} \mathrm{cm} \mathrm{cm}^{-2}$ in $4.6 \mathrm{M}$ $\mathrm{H}_{2} \mathrm{SO}_{4}$ : 1) 3 minutes after the start of OCV (see Fig. 3); 2) passivation with $\mathrm{PbSO}_{4}$. 

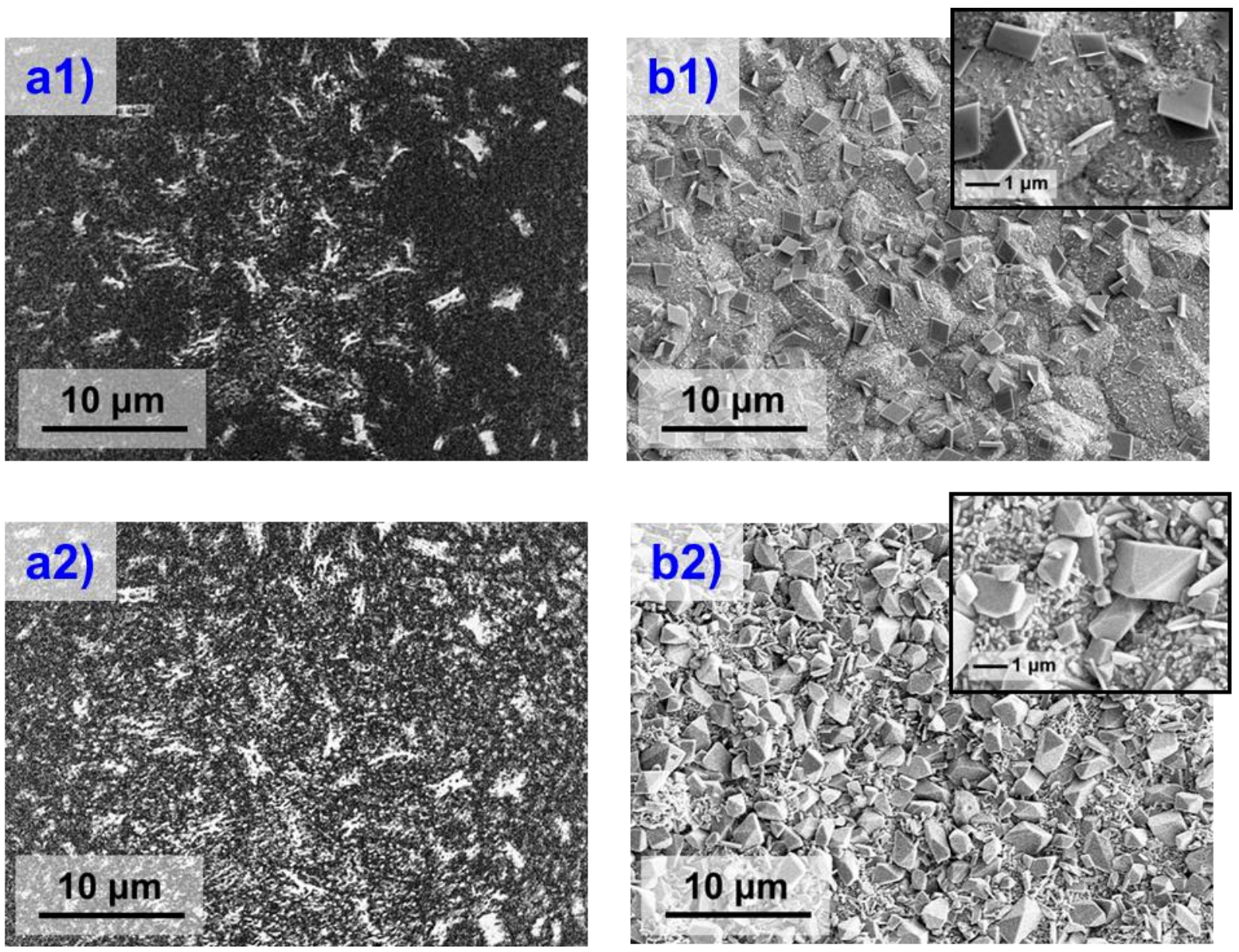

Figure 2. a) TXM and b) SEM images taken during oxidation of $\mathrm{Pb}$ at $50 \mu \mathrm{A} \mathrm{cm} \mathrm{c}^{-2}$ in $4.6 \mathrm{M}$ $\mathrm{H}_{2} \mathrm{SO}_{4}$ with 26 ppm sodium lignosulfonate: 1) 3 minutes after the start of OCV (see Fig. 3); 2) passivation with $\mathrm{PbSO}_{4}$. 


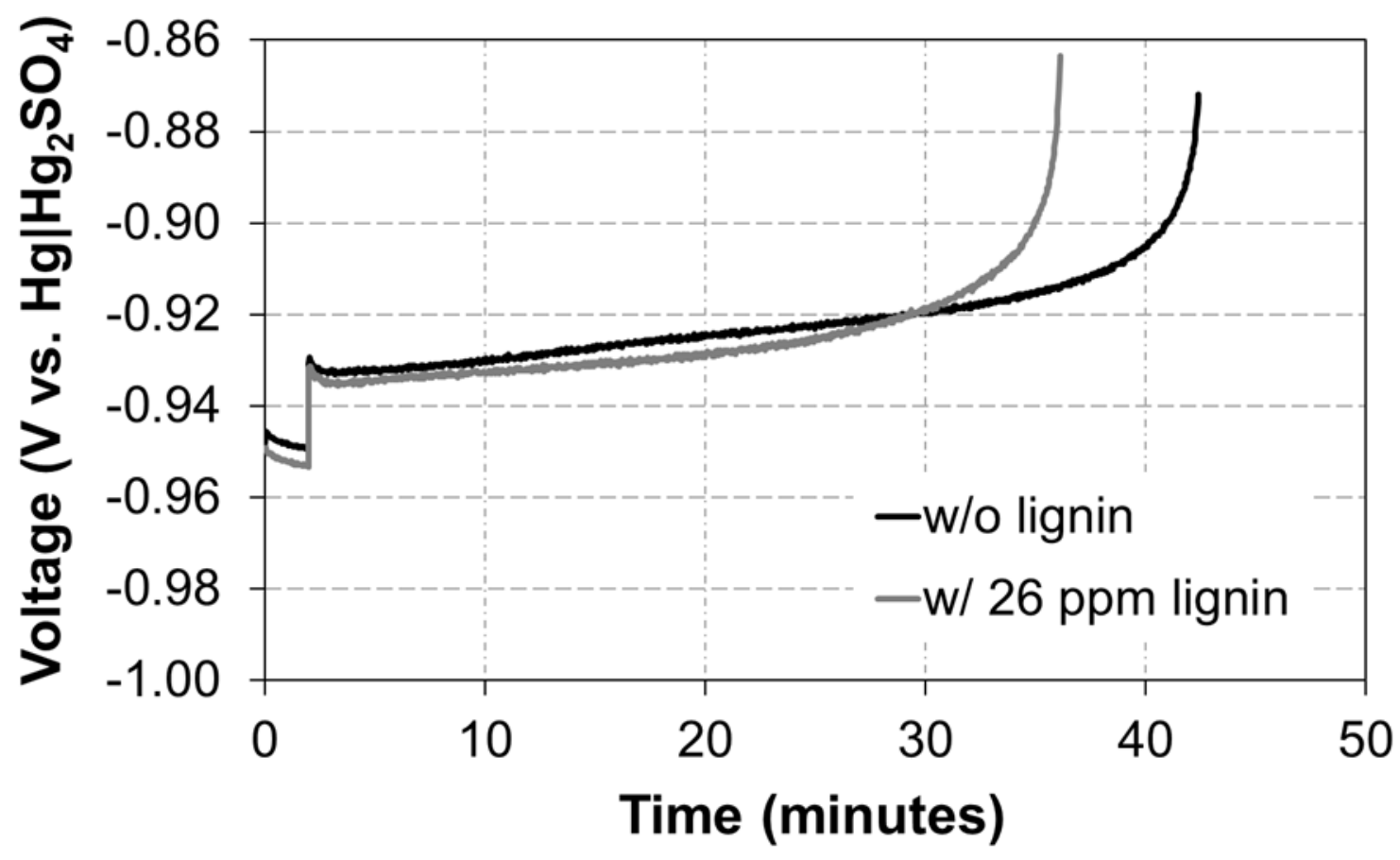

Figure 3. Voltage response of TXM experiments without and with $26 \mathrm{ppm}$ sodium lignosulfonate added to the electrolyte. For both, $\mathrm{Pb}$ electrode was held at open-circuit voltage for 2 minutes, followed by a galvanostatic oxidation at $50 \mu \mathrm{A} \mathrm{cm}^{-2}(-0.87 \mathrm{~V}$ cutoff). 
a)

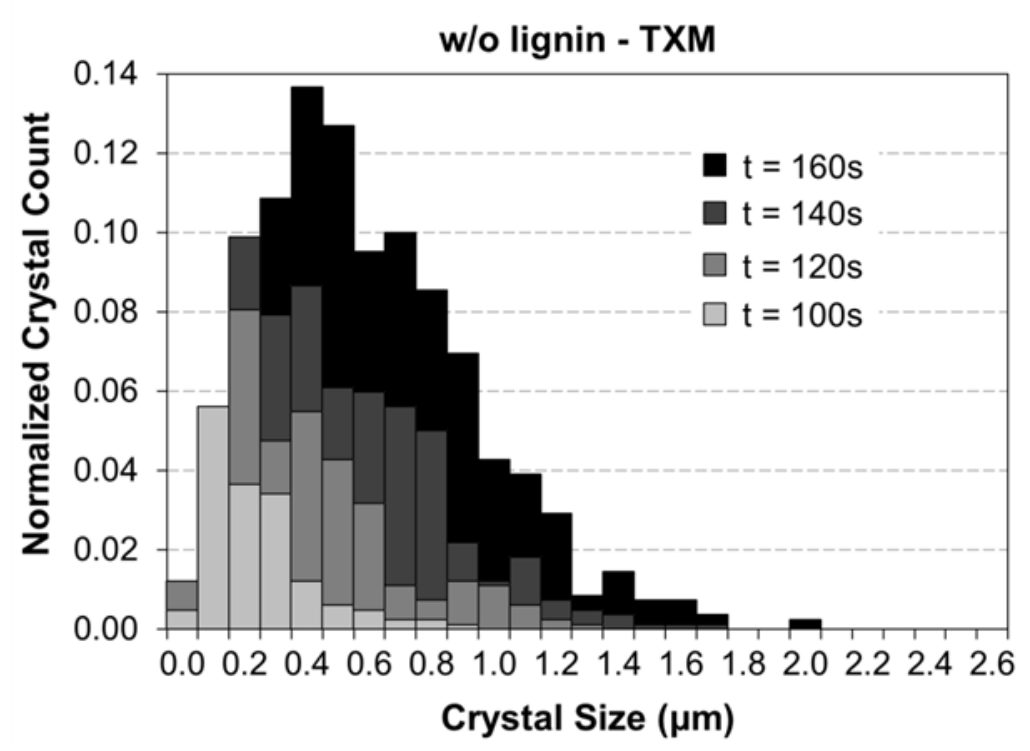


a)

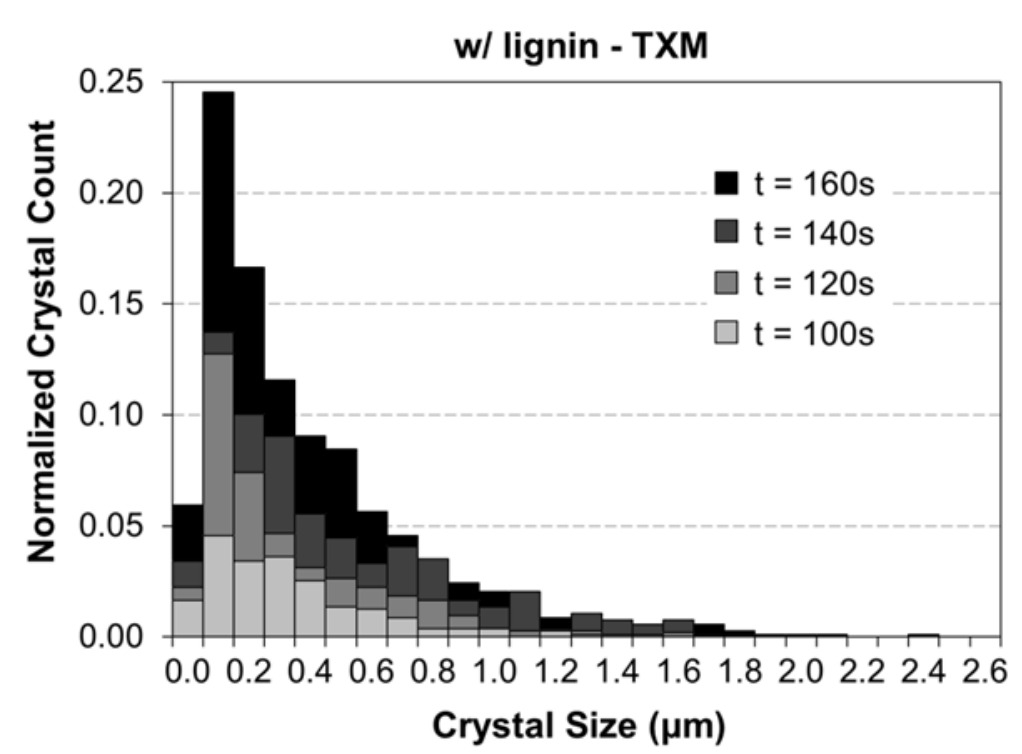

b)

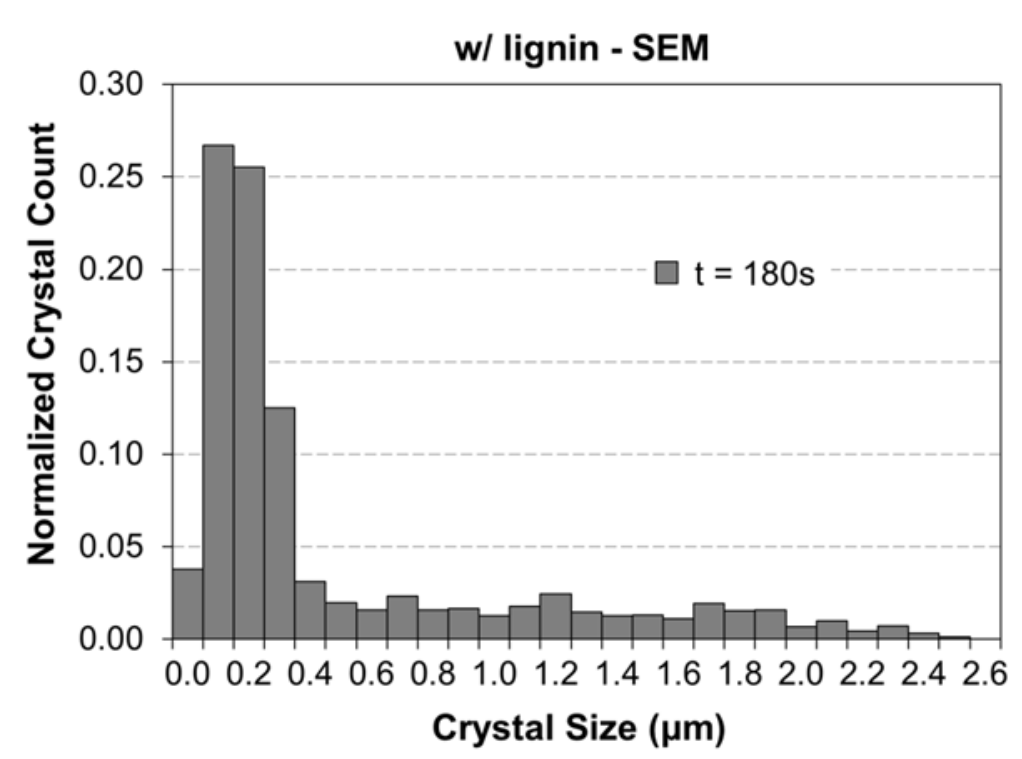

Figure 5. Distribution of crystal sizes for $\mathrm{PbSO}_{4}$ grown on $\mathrm{Pb}$ in $4.6 \mathrm{M} \mathrm{H}_{2} \mathrm{SO}_{4}$ with $26 \mathrm{ppm}$ sodium lignosulfonate: a) TXM experiment, b) separate experiment on electroplated $\mathrm{Pb}$. Time in figures is in reference to the start of OCV (Fig. 3). 
a)

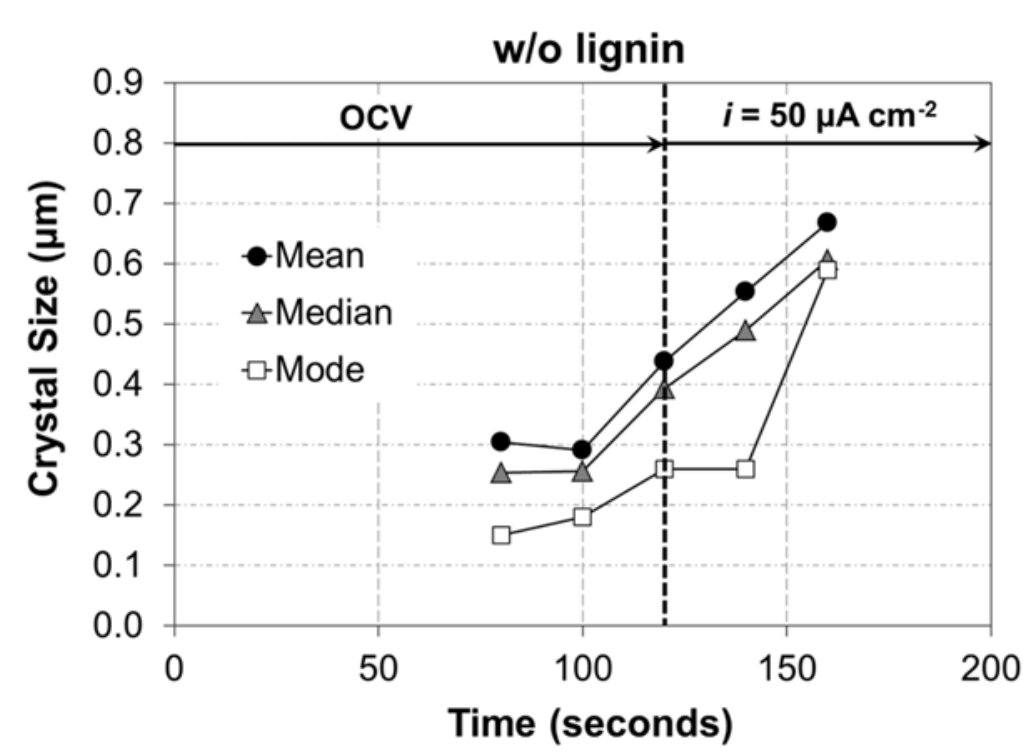

b)

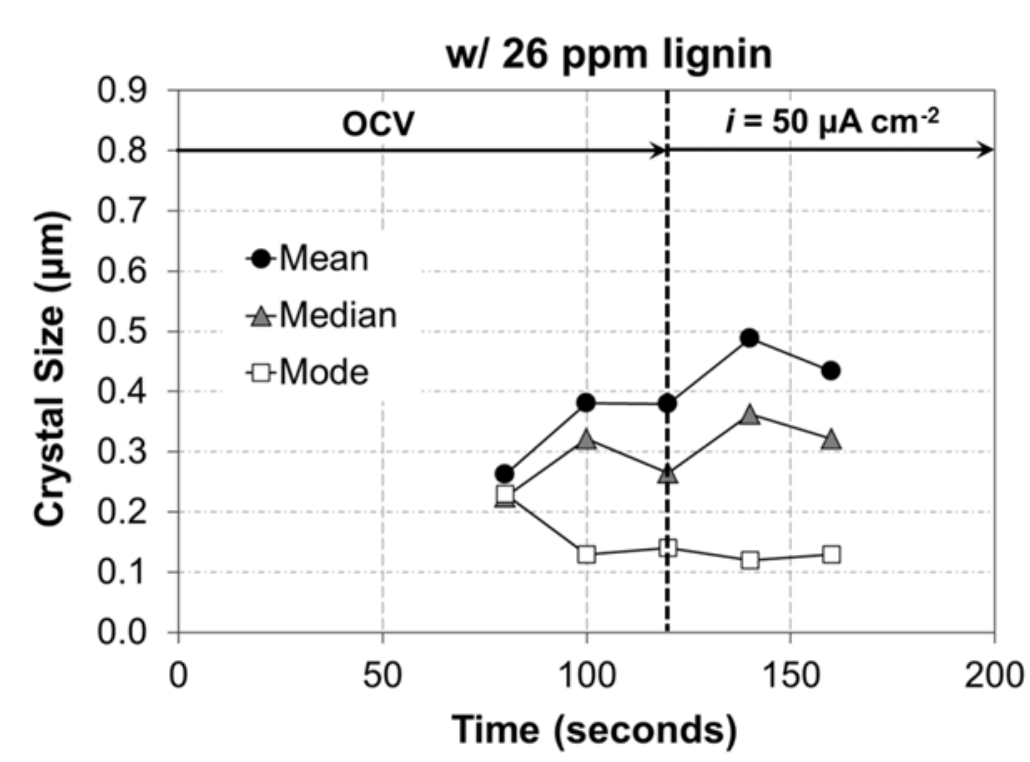

Figure 6. Mean, median, and mode of the crystal sizes obtained from the TXM experiments a) without and b) with 26 ppm sodium lignosulfonate in the electrolyte. 

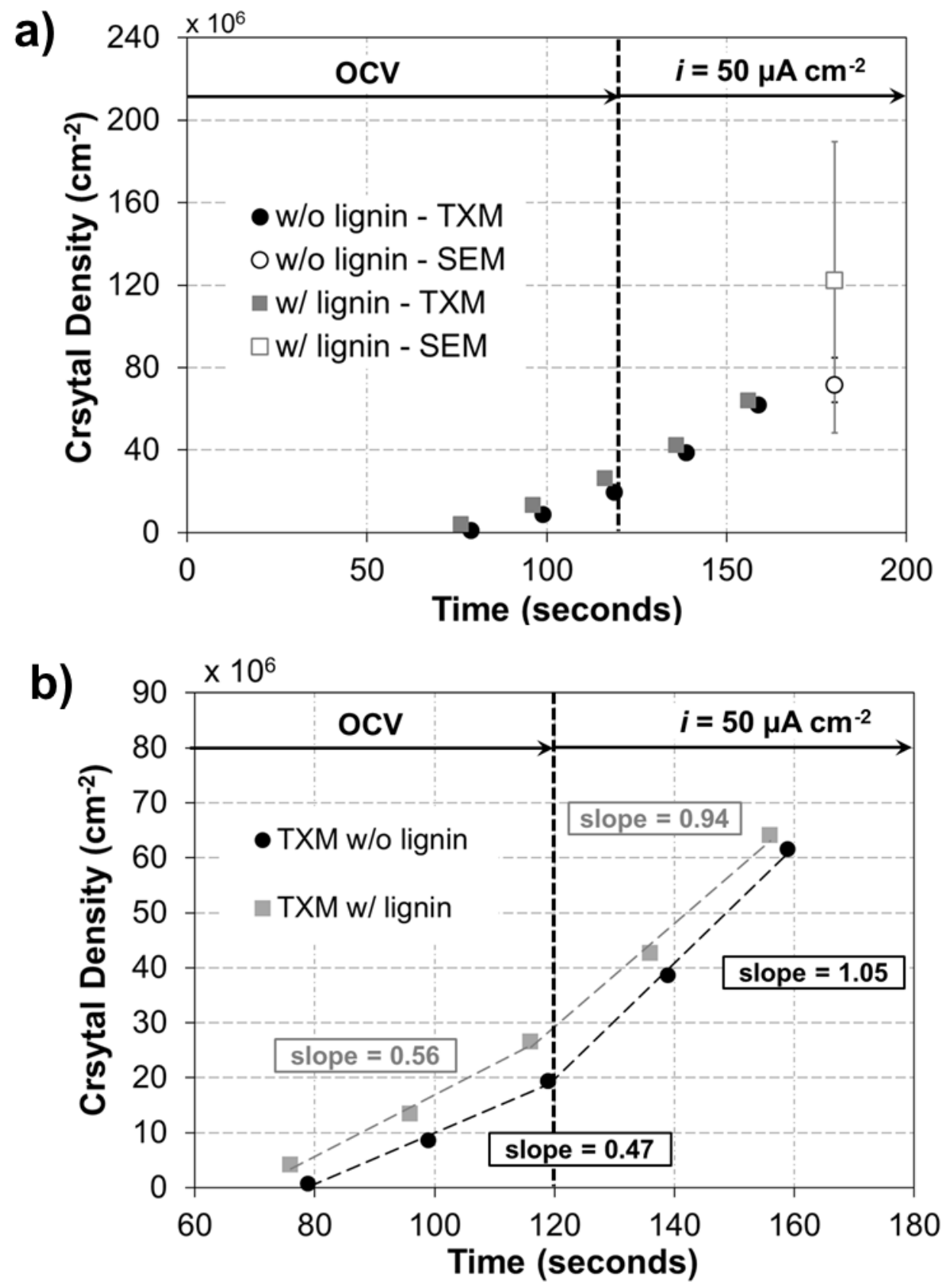

Figure 7. $\mathrm{PbSO}_{4}$ crystal density on $\mathrm{Pb}$ in $4.6 \mathrm{M} \mathrm{H}_{2} \mathrm{SO}_{4}$ without and with 26 ppm sodium lignosulfonate. a) Comparison of SEM and TXM data. Error bars on SEM data indicate maximum and minimum values observed from multiple images of the same sample. b) Close-up of TXM data. Slopes of fits have units $\left[\mathrm{x} 10^{6} \mathrm{~cm}^{-2} \mathrm{~s}^{-1}\right]$. 


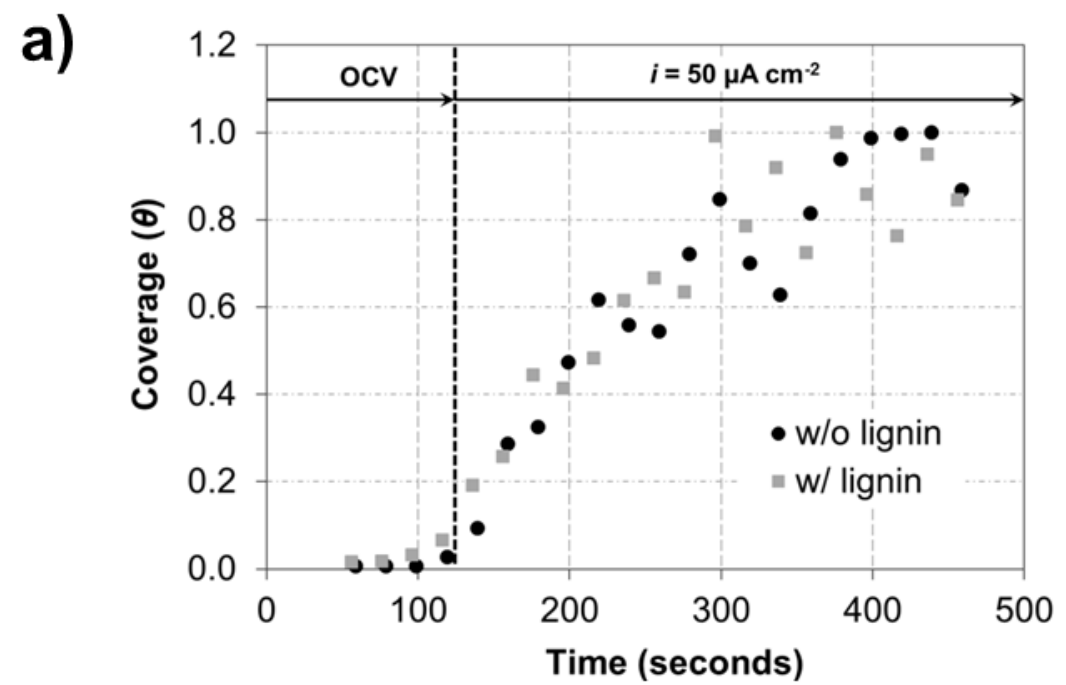

b)

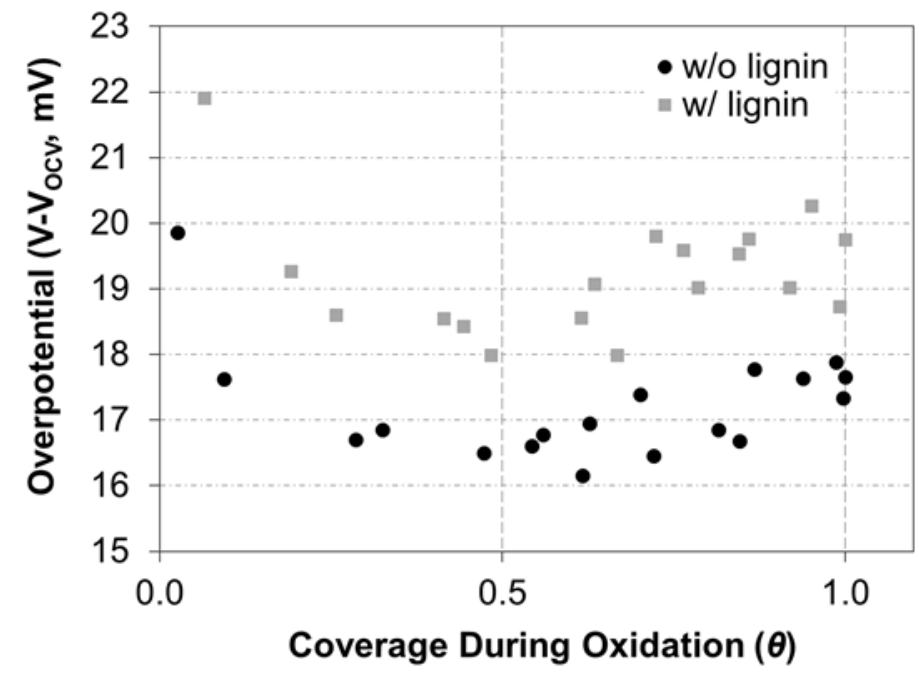

Figure 8. a) $\mathrm{PbSO}_{4}$ surface coverage vs. time during the OCV and galvanostatic experiments. b) Overpotential vs. surface coverage during the oxidation experiment. 
a1)

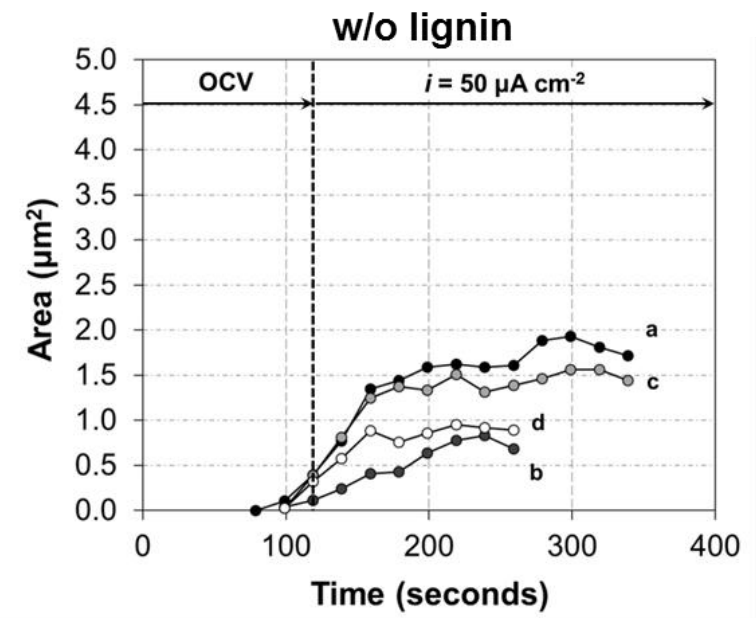

a2)

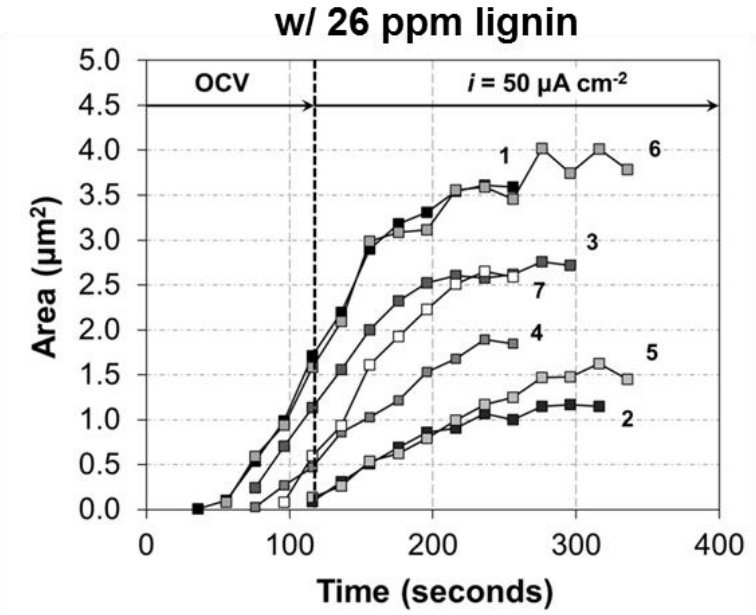

b1)

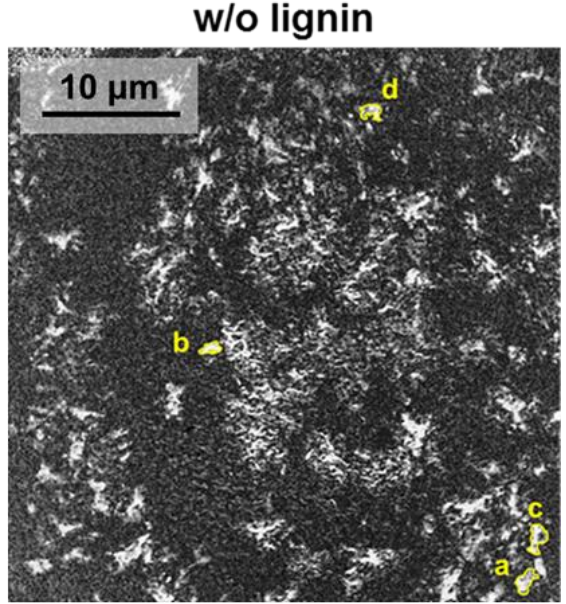

b2)

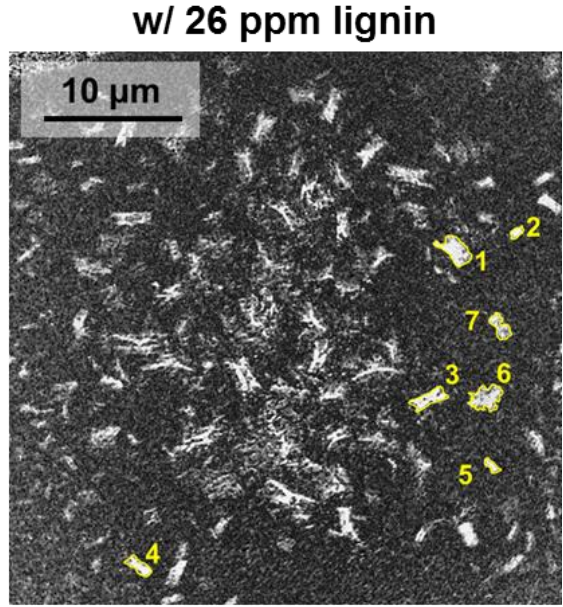

Figure 9. a) Initial increase in the projected area for a select group of crystals. b) TXM image of crystals used in study at $\mathrm{t}=180$ seconds. Results are from experiments 1) without and 2) with 26 ppm sodium lignosulfonate in the electrolyte. 

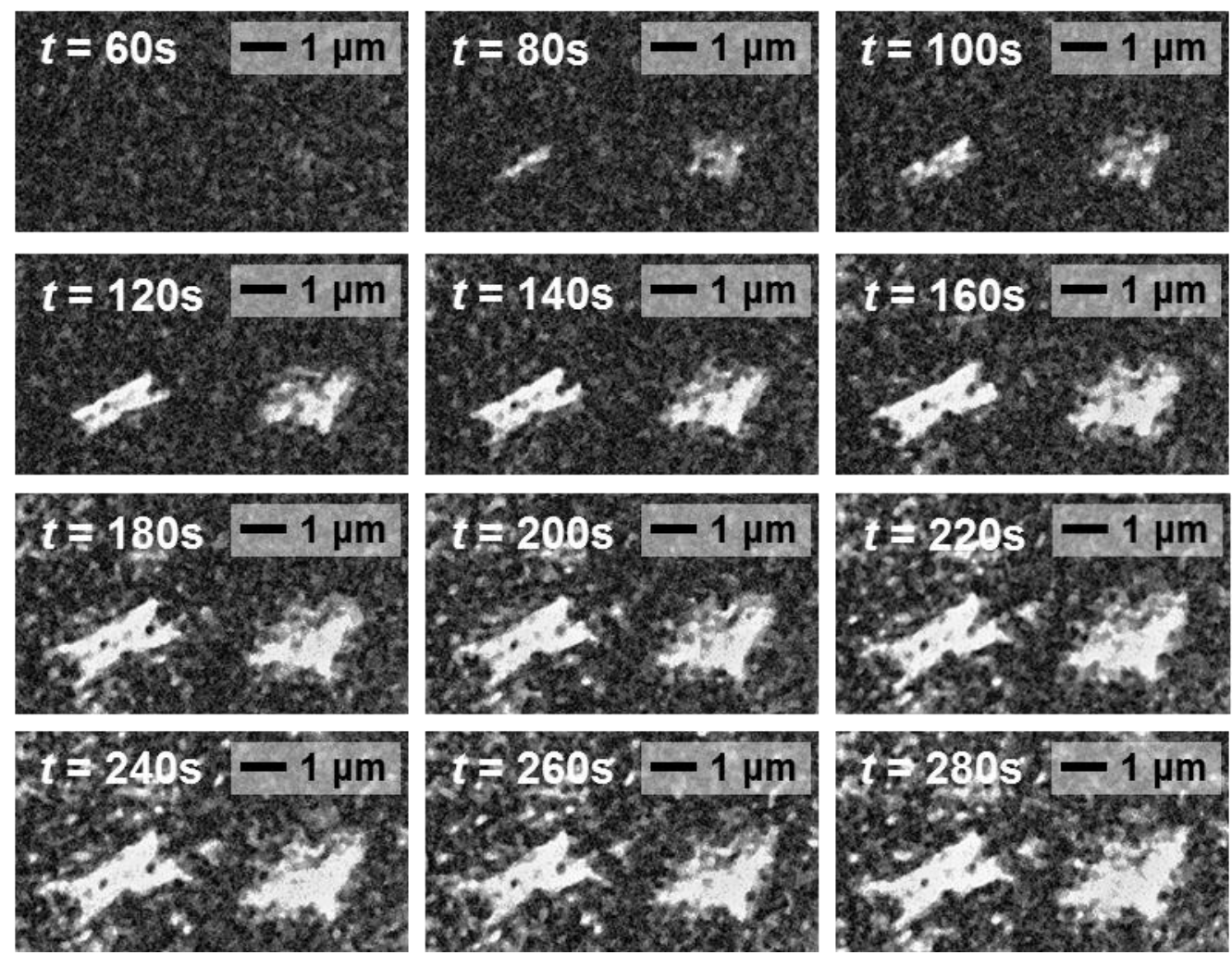

Figure 10. TXM images of crystals 3 and 6 (Fig. 9, image b2) grown at $50 \mu \mathrm{Acm}^{-2}$. Times are in reference to the start of OCV (Fig. 3). 


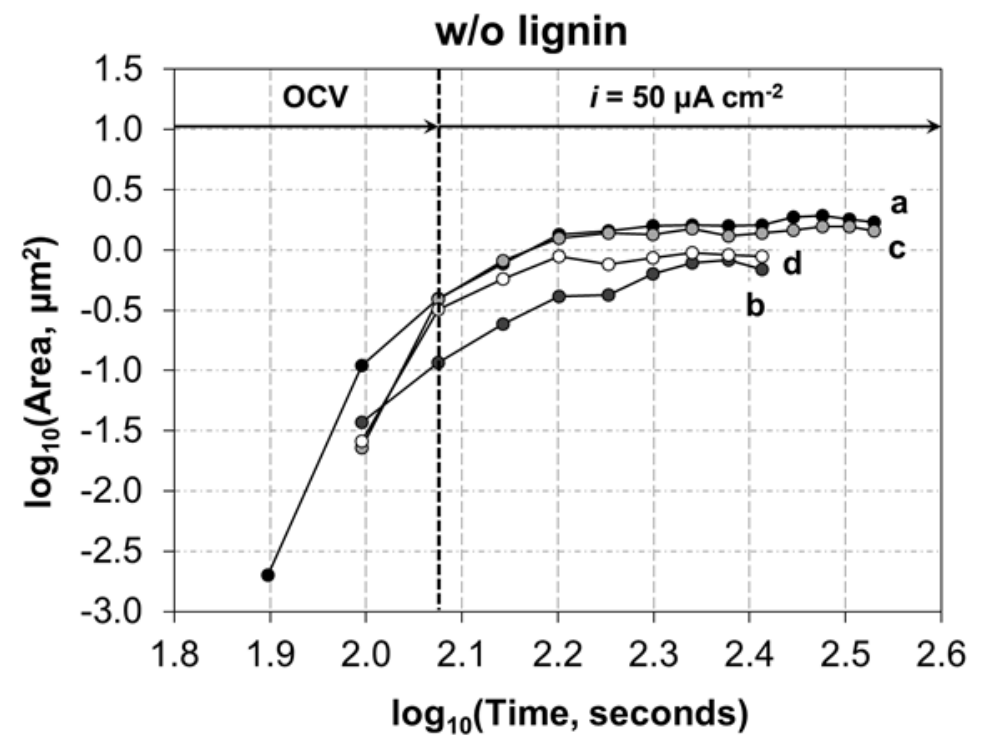

b)

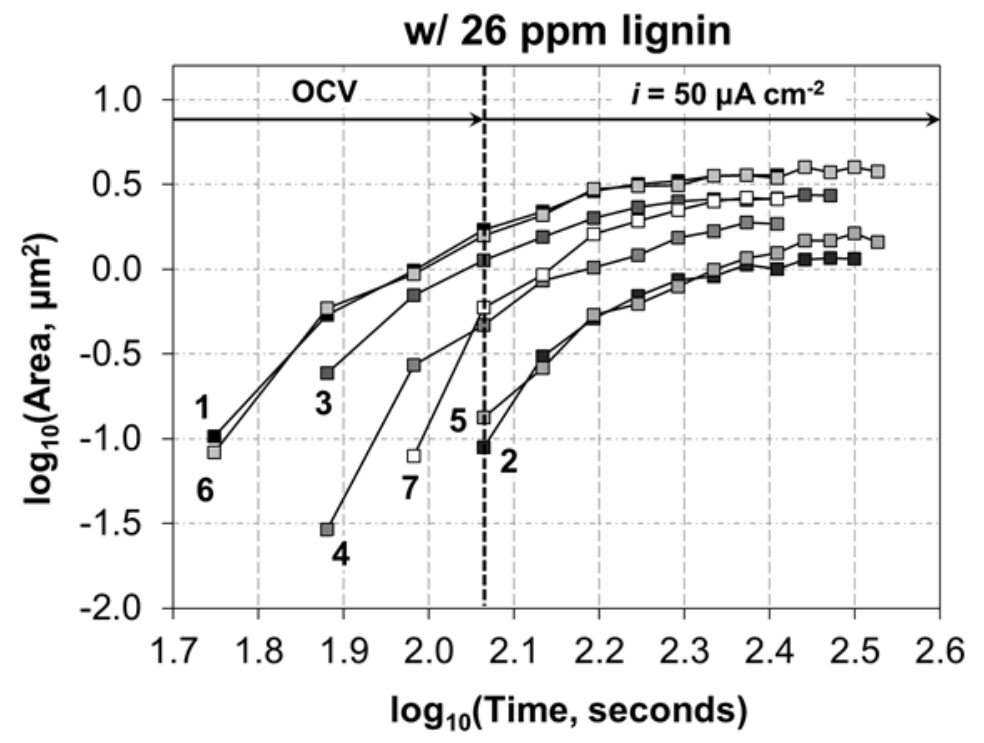

Figure 11. Logarithmic plots of crystal area vs. time for the projections of individual crystals in experiments a) without and b) with 26 ppm sodium lignosulfonate in the electrolyte. 
II) Region where large crystal growth stops/slows (Fig. 9)

III) Time when $\mathrm{PbSO}_{4}$ film coalesces [24]

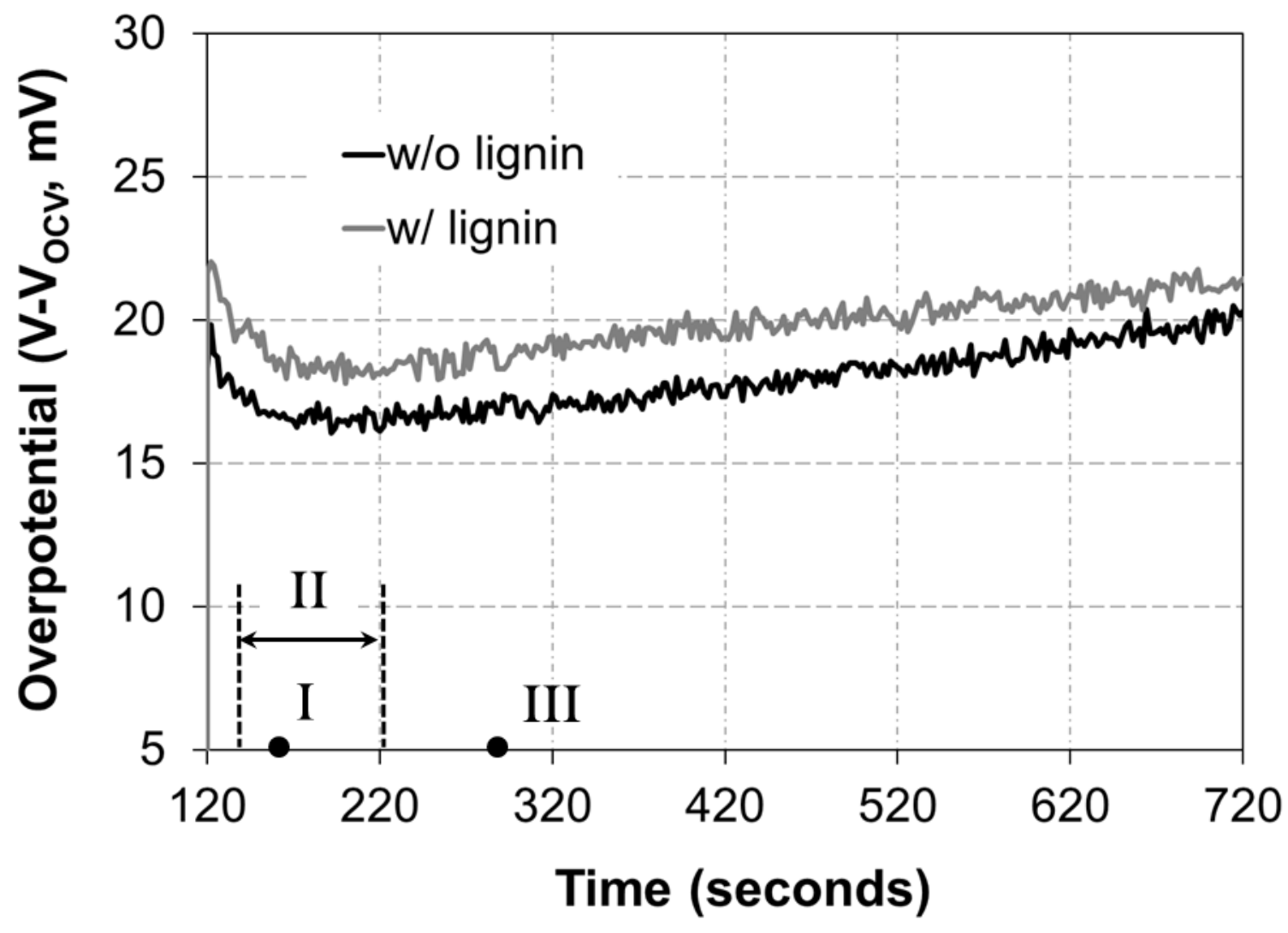

Figure 12. Initial voltage response of galvanostatic oxidation at $50 \mu \mathrm{A} \mathrm{cm}{ }^{-2}$ in TXM set-up for experiment without and with $26 \mathrm{ppm}$ sodium lignosulfonate in the electrolyte. I, II, and III mark the occurrence of specific events during the film growth. 